\title{
Inundação na Bacia Hidrográfica do Rio Duas Bocas (ES): um evento extremo em 2013
}

\author{
Flood in the Watershed Area of the River Duas Bocas - ES: an extreme event in \\ 2013
}

\section{Inundación en la Cuenca Hidrográfica del Rio Duas Bocas (ES): un evento extremo en 2013}

\author{
Eberval Marchioro ${ }^{1}$ \\ https://orcid.org/ 0000-0003-0207-6087 \\ Francini Nunes Coutinho ${ }^{2}$ \\ https://orcid.org/ 0000-0003-4057-4853
}

\begin{abstract}
RESUMO: Inundação é um processo que ocorre em diferentes espaços geográficos, ocasionando problemas socioambientais. Em função disso, este trabalho possui como objetivo mapear e analisar o processo de inundação associado ao evento extremo de precipitação pluvial do mês de dezembro de 2013 na bacia hidrográfica do rio Duas Bocas (ES) e o efeito do remanso de água promovido pelo rio Santa Maria da Vitória (ES). Para tal, foram utilizados dados de precipitação e vazão, da Agência Nacional de Águas e do Instituto Capixaba de Pesquisa e Extensão Rural e os dados cartográficos fornecidos pela empresa Hiparc Ltda. Os resultados apontam que em dezembro de 2013 a precipitação pluvial foi maior que a normal climatológica, sendo que somente no referido mês o desvio positivo de precipitação foi de 413,8 milímetros, concentrados principalmente entre a porção média e baixa da bacia, devido à atuação da Zona de Convergência do Atlântico Sul. O percentual inundado na bacia hidrográfica do rio Duas Bocas foi de 9,69\%, sendo que, desta, 98,96\% ocorreram entre as cotas altimétricas de 1,65 e 10 metros de altitude. Foi verificado o efeito de barramento e remanso provocado pelo rio Santa Maria da Vitória sobre o exutório do rio Duas Bocas.
\end{abstract}

PALAVRAS-CHAVE: Hidrologia. Inundação. Sub-bacia.

ABSTRACT: Flooding is a phenomenon that occurs in different geographical spaces, causing several socioenvironmental problems. Thus, this work's objective is to evaluate and map the process of flooding associated with the extreme rainfall event of December 2013, in the Duas Bocas River watershed (ES) and the backwater effect promoted by the Santa Maria da Vitória river (ES). To this end, we used rainfall data from the National Agency of Water and the State Rural Research and Extension Institute and cartographical data provided by Hiparc Company Ltda. The results show that December 2013's accumulated rainfall was above the climatological normal, with a positive deviation of $413.8 \mathrm{~mm}$, concentrated mainly among the middle and lower portions of the watershed, associated

\footnotetext{
1 Doutorado em Geografia pela UFRJ. Professor do Departamento de Geografia da Universidade Federal do Espírito Santo. E-mail: ebervalm@gmail.com.

${ }^{2}$ Graduação em Geografia. Universidade Federal do Espírito Santo. E-mail: francini.coutinho@yahoo.com.br.
} 
to the activity of the South Atlantic Convergence Zone. The flooded area in the Duas Bocas River watershed was $9,69 \%$ of the total area, with $98.96 \%$ of the flooded area with altitude ranging between 1.65 and $10 \mathrm{~m}$. It was verified that the the river Santa Maria da Vitória acted as a dam over the outlet point of the Duas Bocas river, contributing to its flooding.

KEYWORDS: Hydrology. Flood. Watershed.

RESUMEN: La inundación es un fenómeno que ocurre en diferentes espacios geográficos, generando un sin número de problemas socio-ambientales. Así, este trabajo tiene como objetivo principal, analizar y mapear el proceso de inundación asociado al evento pluvial extremo de diciembre de 2013 de la Cuenca Hidrográfica del Río Duas Bocas (ES) y el efecto del remanso hidráulico promovido por el Río Santa María de la Vitória (ES). Para cumplir este objetivo, fueron utilizados datos de precipitación y del caudal de la Agencia Nacional de Agua y del Instituto Capixaba de Investigación, Asistencia y Extensión Rural; adicionalmente, datos cartográficos proporcionados por la empresa Hiparc LTDA. Los resultados muestran que, durante el año y mes de diciembre 2013, la precipitación ha sido más significativa que la normal climatológica, demostrando un desvío positivo de 413.8mm solamente en diciembre, con la lluvia concentrada principalmente en la región media y baja de la cuenca. El área total inundada de la cuenca hidrográfica del Río Duas Bocas fue de 9,69\% siendo que $98.96 \%$ ocurrió entre las cotas altimétricas de 1,65 y $10 \mathrm{~m}$ de altitud, alcanzando, en algunos locales, una profundidad de hasta 1.5 metros entre el fondo y la superficie acuática. Fue verificado el efecto barrero y el remanso provocado por el río Santa Maria de la Vitória sobre el estuario del río Duas Bocas favoreciendo su inundación. El principal uso y cobertura del suelo fue afectado directamente a pastos (llanuras para ganadería), el uso dominante en la cuenca hidrográfica.

PALABRAS CLAVE: Hidrología. Inundación. Cuenca.

\section{INTRODUÇÃO}

A convivência do homem com a inundação promovida pelos cursos fluviais ocorre desde os primórdios de seu processo de apropriação do espaço geográfico, uma vez que, o homem procurou se fixar inicialmente próximo a rios, porque deles retirava alimento, ocupava para moradia e os utilizava para o transporte (TUCCI, 2004).

Por definição, inundação é o processo de transbordamento das águas sobre as áreas próximas a ela, sendo essas áreas denominadas de planície de inundação (GOUDIE, 2004). Esse fenômeno, segundo Wolman e Leopold (1957), é resultante de um conjunto de fatores que podem ser agrupados em naturais (precipitação, características fisiografias das bacias e efeito de remanso entre rios, entre outros) e antrópicos (como a transformação no uso e cobertura da terra, construção de represas etc.).

A partir da década de 1970, Trigg et al. (2013) salientam que, em função da importância do transbordamento das águas e de seus reflexos sobre a população, têm sido realizados diversos esforços para se compreender tal fenômeno no espaço geográfico e propor medidas de mitigação socioambiental. 
Assim, verificam-se diferentes metodologias para os estudos da inundação que podem ser agrupadas dentre aquelas que utilizam os modelos matemáticos (ALCRUDO, 2016; ARDUINO; REGGIANI; TODINI, 2005; BRUNNER, 2016; PENDER, 2006; PRAKASH; ROTHAUGE; CLEARY, 2014; WOODHEAD et al., 2007) e aquelas associadas ao mapeamento de áreas de inundação por meio de imagens de satélites, como observado em trabalhos de Smith (1997), Schumann et al. (2009), Pôssa e Ventorini (2014), Hora e Gomes (2009), Magalhães et al. (2011), Ticehurst et al. (2015) e Wang et al. (2015), dentre outros.

O estudo dos processos e o mapeamento das áreas atingidas pela inundação tem recebido ainda maior atenção devido à expansão da apropriação do espaço geográfico para múltiplos fins, dentre eles aqueles associados ao aumento dos centros urbanos e das áreas agrícolas, que se expandem desordenadamente e sem considerar a possibilidade da inundação que corrobora o agravamento das populações atingidas (CENTRO DE ESTUDOS E PESQUISAS DE DESASTRES NATURAIS, 2013.

Diversos são os exemplos de casos de inundação no sudeste brasileiro, tal como destacado por Costa (2001), que as analisou no estado do Rio de Janeiro, abordando suas inter-relações naturais e antrópicas; Cajazeiro (2012), que analisou a suscetibilidade à formação de inundação das bacias do ribeirão Arrudas e do córrego Onça a partir de índices morfométricos e de impermeabilização; Pôssa e Ventorini (2014), que mapearam as áreas de inundação na bacia do ribeirão Água Limpa em São João Del Rey, onde constataram que houve forte contribuição antrópica para a ocorrência.

Nesse sentido, estudos que tratam desta temática são de fundamental importância para a sociedade, principalmente aqueles associados à bacia hidrográfica, pelos quais se pode conhecer os fluxos de energia e matéria. Assim, em função da importância do tema inundação, este trabalho possui como objetivo mapear e analisar o processo de inundação, associado ao evento extremo de precipitação pluvial do mês de dezembro de 2013, na bacia hidrográfica do rio Duas Bocas (ES) e o efeito de remanso promovido pelo rio Santa Maria da Vitória (ES).

\section{ÁREA DE ESTUDO}

A Bacia hidrográfica do rio Duas Bocas (BHRDB) está situada entre as coordenadas $20^{\circ} 12^{\prime} 01,28^{\prime \prime}$ e $20^{\circ} 17^{\prime} 24,90^{\prime \prime}$ de latitude sul e 40²3'06,35 e 40³2'07,88" de longitude oeste, abrangendo os municípios de Cariacica, Viana e Santa Leopoldina, sendo uma sub-bacia do Rio Santa Maria da Vitória, que drena suas águas para a Baia de Vitória (ES) (Figura 1).

A BHRDB possui uma extensão territorial de 92,27 quilômetros quadrados, ou 9.226,89 hectares, sendo que a maior extensão areal da bacia hidrográfica encontra-se no município de Cariacica, que pertence à Região Metropolitana de Vitória. O município de 
Cariacica faz limite com os municípios de Serra, Vitória, Vila Velha, Viana, além de Domingos Martins e Santa Leopoldina, que compõem a região serrana do estado.

Figura 1 - Localização da bacia hidrográfica do rio Duas Bocas em relação à bacia do rio Santa Maria da Vitória (ES)

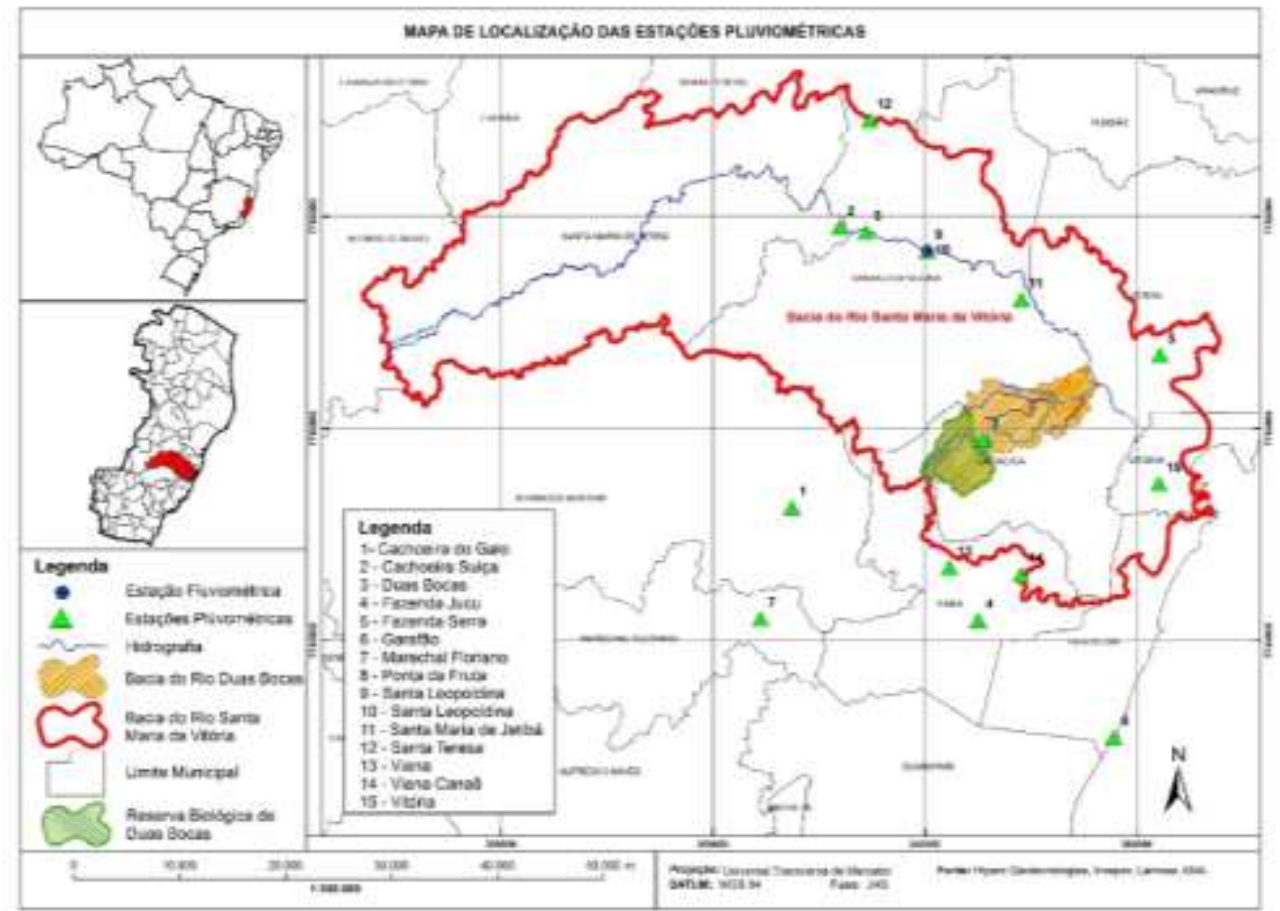

Fonte: os próprios autores (2020).

As cabeceiras de drenagem da BHRDB estão inseridas na Reserva Biológica de Duas Bocas (ReBio) (Figura 1), podendo-se destacar os córregos Sertão Velho, Panelas, NaiaAssú e Pau Amarelo, que são os principais tributários do rio Duas Bocas, como destacam Perrone (1995), Marchioro e Barroso (1996) e Marchioro et al. (2017).

Segundo Amorim (2014), na escala de 1:25.000 e baseado na proposta de Strahler (1957), a BHRDB apresenta-se hierarquicamente classificada como de $5^{\text {a }}$ ordem, possuindo densidade de drenagem de 0,11 , densidade de seguimentos 3,02 , comprimento do rio principal de 23,03 quilômetros. De acordo com a metodologia da Embrapa (2013), a declividade predominante na BHRDB é de 8 a 20\% (relevo ondulado), que ocorre por $49,94 \%$ da área, e 3 a $8 \%$ (relevo suave ondulado), encontrado em $24,83 \%$ da área.

O mapa de distribuição de precipitação, elaborado por Bastos et al. (2015), indica que, para a normal climatológica do período de 1983 a 2013, a BHRDB possui uma variação pluviométrica de 1.307 a 1.656 milímetros, apresentando como os meses mais chuvosos novembro, dezembro e janeiro, e, os meses mais secos de junho a agosto.

De acordo com a normal climatológica, a BHRDB apresenta a maior concentração de chuva na porção a montante da bacia (próximo às cabeceiras), o que a caracteriza por 
chuva orográfica na maior parte do ano, associado ao processo de evapotranspiração da Mata Atlântica presente na Reserva Biológica de Buas Bocas (ReBio). A temperatura média da BHRDB é de $24^{\circ} \mathrm{C}$, sendo que no verão ultrapassa os $33^{\circ} \mathrm{C}$. Os ventos predominantes são dos quadrantes norte-nordeste, sendo modificados pela entrada de massas de ar frio oriundas do quadrante sul (sudoeste/sudeste) (MARCHIORO, 2012). As características de precipitação e temperatura são dinamizadas pela ação das massas de ar, da Zona de Convergência do Atlântico Sul e pela Zona de Convergência de Umidade (MARCHIORO; SILVA; CORREA; 2016).

A BHRDB é constituída geologicamente pelo Complexo Nova Venécia, Granito Maciço Vitória, Grupo Barreiras e Depósitos Aluvionares (QUEIROGA et al., 2012), contemplando geomorfologicamente, as unidades dos Patamares Escalonados do Sul Capixaba, Colinas e Maciços Costeiros, Tabuleiros Costeiros, e a Acumulação Fluvial (INSTITUTO JONES SANTOS NEVES, 2012). Pedologicamente, a BHRDB abrange os Cambissolos, Latossolos Vermelho-Amarelo/Argissolos e Neossolos Litólicos (EMBRAPA, 2013).

O uso e a cobertura da terra da BHRDB, para o ano de 2012, apresentou, segundo Santos e Marchioro (2018, 2020), o predomínio de Mata Nativa (48,27\%), Pastagem (31,51\%), Cultivo Agrícola - Banana (6,78\%). É importante destacar que essa Mata Nativa (Mata Atlântica) se encontra predominantemente nos limites da Reserva Biológica de Duas Bocas (ReBio), onde estão as cabeceiras de drenagem o rio Duas Bocas.

\section{METODOLOGIA}

A escolha da bacia hidrográfica do rio Duas Bocas para o desenvolvimento desse trabalho deveu-se ao fato de que, desde 1996, estão sendo desenvolvidos trabalhos diversos de hidrologia e hidrossedimentologia, tal como apresentado por Perrone (1995), Marchioro e Barroso (1996), Amorim (2014), Cupertino, Santos e Marchioro (2015), Lopez e Marchioro (2018) e Santos e Marchioro (2018, 2020), sem, contudo, abordarem a temática deste trabalho.

Para o mapeamento da área inundada na bacia hidrográfica do rio Duas Bocas optouse pelo período de 9 a 26 de dezembro de 2013, que foi marcado por chuvas acumuladas e elevadas em toda a Região Metropolitana de Vitória (RMGV) e, também, devido aos relatos de moradores residentes nas áreas inundadas da bacia, que indicaram que nesse período ocorreu a maior inundação que já presenciaram.

Para o mapeamento das áreas inundadas, foram utilizados dados fluviométricos, curva de nível, hidrografia, imagens aéreas, dados pluviométricos, os quais apresentam as seguintes informações técnicas: 
a) Com o propósito de analisar os efeitos da vazão do rio Santa Maria da Vitória sobre a bacia do rio Duas Bocas (efeito de barramento), foram utilizados os dados de vazão para o período de 1950 a 2013, e cota para o período de 1970-2013 do rio Santa Maria da Vitória, disponibilizados no site da Agência Nacional de Águas (ANA), da estação localizada no Município de Santa Leopoldina (ES), código 5713000. Com os referidos dados de vazão do rio Santa Maria foram elaborados gráficos de vazão média anual e mensal do período de 1950 a 2014, vazões máximas, médias e mínimas mensais do rio Santa Maria da Vitória, em 2013 e 2014, e o comparativo entre vazão média mensal de 2013 e 2014 e vazão média anual de 2013 do mesmo rio.

b) Os dados de curvas de nível e hidrografia foram obtidos junto ao Laboratório de Monitoramento e Modelagem de Sistemas Ambientais (Lamosa), cedidos pela empresa Hiparc Ltda, apresentando as seguintes características: b1) curvas de nível, com equidistâncias de 5 em 5 metros; e b2) hidrografia - foram obtidas a partir das curvas de níveis de 5 em 5 metros (ENVIRONMENTAL SYSTEMS RESEARCH INSTITUTE, 2012).

c) Os dados pluviométricos correspondem a 14 estações localizadas ao redor da área de estudo, composta pela normal climatológica entre o período de 1983 e 2013, disponibilizado pelo Instituto Capixaba de Pesquisa e Extensão Rural Extensão Rural (INCAPER) e uma estação situada no interior da bacia, que foi disponibilizada pela Agência Nacional de Águas (ANA) (Figura 1). Para a confecção do mapa de distribuição de chuva da BHRDB foi utilizado o modelo de interpolação Spline, pois foi o que melhor se adequou, sendo estabelecidos cinco intervalos de classe, buscando melhor representação da precipitação pluvial na bacia.

O método empregado para a confecção das curvas de nível foi o modelo semiautomático, com pares estereoscópicos aerotriangulares, por meio das correlações entre as imagens fotográficas aéreas digitais. Para isso, utilizou-se o software MATCH-T da família INPHO, para a geração automática do Modelo Digital do Terreno (MDT). Em seguida, o modelo gerado na etapa anterior foi carregado, com grade de pontos de controle, para ajuste manual de possíveis erros do programa, com o objetivo de fixar todas as cotas no terreno. O software empregado nessa etapa foi INPHO DTMaster.

O passo seguinte foi a retificação da altimetria, em que as curvas de nível foram geradas com base no Modelo Digital do Terreno (MDT), com equidistância de 5 metros e mestras a cada 25 metros, com precisão 1:10.000, por meio do uso do software SCOP++, da família INPHO. O processo foi finalizado com a edição gráfica das curvas de nível nos softwares Autodesk Civil3D e ArcGis ${ }^{T M}$ 10.3.

A restituição da hidrografia foi confeccionada na escala 1:10.000, tendo como base as feições tridimensionais do Modelo Digital do Terreno (MDT). Os softwares utilizados para a 
restituição 3D foram $D V P$ e Summit. A edição em 3D e 2D foi realizada a partir dos softwares Autodesk Civil3D e ArcGis ${ }^{T M} 10.3$.

Para o mapeamento das áreas de inundação utilizou-se as imagens aéreas do Google Earth Pro, com data de 26 de dezembro de 2013, que foi o período de ocorrência da inundação. O processo de delimitação da área de inundação correspondente ao período chuvoso foi pré-confeccionado no Google Earth Pro, no qual se utilizou a ferramenta polígono para delimitar a área de inundação presente na imagem.

O polígono gerado foi salvo na extensão Keyhole Markup Language (KML) para ser utilizado no Arc Map $10^{T M}$ (ENVIRONMENTAL SYSTEMS RESEARCH INSTITUTE, 2012). Esse polígono foi transferido para o Plano de Informação Cartografia (shapefile), onde foi inserida a seguinte referência: WGS 84, Fuso 24K; coordenadas Universal Transversa de Mercator (UTM). Em seguida, o polígono foi ajustado à curva de nível para gerar a delimitação efetiva da área inundada da bacia hidrográfica.

Uma vez obtidos os dados mapeados utilizando-se Google Earth Pro, foi realizado um trabalho de campo no início de abril de 2014 para validação dos dados mapeados, levandose em consideração os relatos de moradores e a identificação de pontos controles com as devidas cotas altimétricas, com o propósito de confirmar e subsidiar ajuste na delimitação das áreas inundáveis.

Os pontos controles foram levantados utilizando-se o equipamento Global Positioning System (GPS), com a finalidade de garantir a precisão das localidades desejadas sobre as imagens aéreas. O GPS apresentou as seguintes propriedades: GARMIN - OREGON 550, erro médio de 5 metros, configurações em World Geodetic System (WGS) 84, Fuso 24K; coordenadas UTM.

Para o mapeamento do uso e cobertura da terra da área inundada da bacia hidrográfica do rio Duas Bocas utilizou-se o ortomosaico de 2012-2013 elaborado pela empresa Hiparc Ltda, cedido ao Laboratório de Monitoramento e Modelagem de Sistemas Ambientais, com resolução de 25 centímetros na escala de 1:10.000, Sistema Geodésico de referências SIRGAS - 2000.

Por fim, foi realizado um teste de coeficiente de correlação de Pearson (n), elaborado entre os dados de série histórica de vazão média anual e precipitação anual do Rio Santa Maria da Vitória. 


\section{RESULTADOS E DISCUSSÃO}

\section{O Ritmo Pluvial da Bacia Hidrográfica do Rio Duas Bocas}

Como pode ser verificado na Figura 02, a média da normal climatológica de 1983-2013 é de 1.538,50 milímetros, sendo que, para os anos de 1983, 2005 e 2013, a precipitação acumulada anual foi superior à média da normal climatológica, com respectivamente, 2.173 milímetros, 2.383,90 milímetros e 2.126,40 milímetros.

Figura 2 - Comparativos de valores anuais de precipitação da BRHDB (1983-2013)

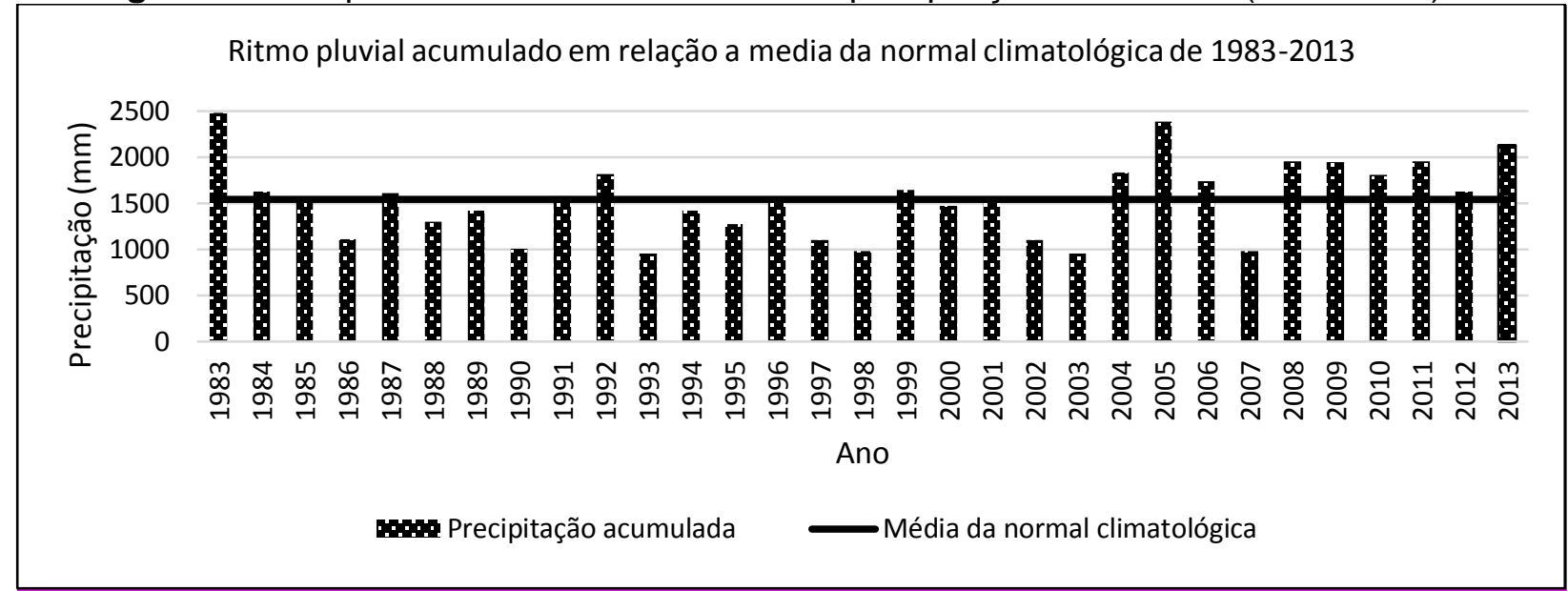

Fonte: Agência Nacional de Águas (2015).

$\mathrm{Na}$ Figura 03 pode-se verificar que o período mais chuvoso para a bacia hidrográfica do rio Duas Bocas se dá de novembro a janeiro, tanto considerando a normal climatológica mensal quanto a precipitação total mensal de 2013. Quando se analisa apenas o ano de 2013, confirma-se, novamente, que os meses mais chuvosos são de novembro a janeiro, mas o volume acumulado em 2013 foi de 1.180,30 milímetros, quando comparado ao mesmo período da normal climatológica, que foi de 686,70 milímetros, ou seja, no período chuvoso de 2013 ocorreu um desvio positivo de precipitação da ordem de 493,60 milímetros.

Analisando apenas o mês de dezembro de 2013 em relação à normal climatológica, verifica-se que em 2013 choveu 685,3 milímetros, volume 2,5 vezes superior à média histórica do mês de dezembro, de 271,5 milímetros. Nessa relação de proporção entre a média histórica mensal e a precipitação total mensal de 2013, o mês de dezembro se destaca em relação aos demais meses do ano, fato que atenta para a relevância do volume de precipitação registrado em dezembro de 2013 na BHRDB.

Com base na normal climatológica do mês de dezembro de 1983-2013, ocorre precipitação acumulada entre 212,64 milímetros a 325,08 milímetros em toda a bacia do rio 
Duas Bocas. Já o mês de dezembro de 2013, apresentou uma precipitação acumulada variando entre o máximo de 808,95 milímetros e mínima de 595,00 milímetros (Figuras 4 e 5). Tanto os valores mínimos quantos os máximos do mês de dezembro de 2013 apresentaram o dobro de precipitação verificado em relação a normal climatológica. Considerando apenas o período do evento analisado, entre 9 a 26 de dezembro, a precipitação pluviométrica diária acumulada na porção média da bacia (uma vez que não se dispõe de outro dado monitorado) foi de 683,9 milímetros.

Figura 3 - Comparativo da precipitação total mensal de 2013 com a precipitação média histórica mensal do período de 1983 a 2013, da Bacia do Rio Duas Bocas (ES)

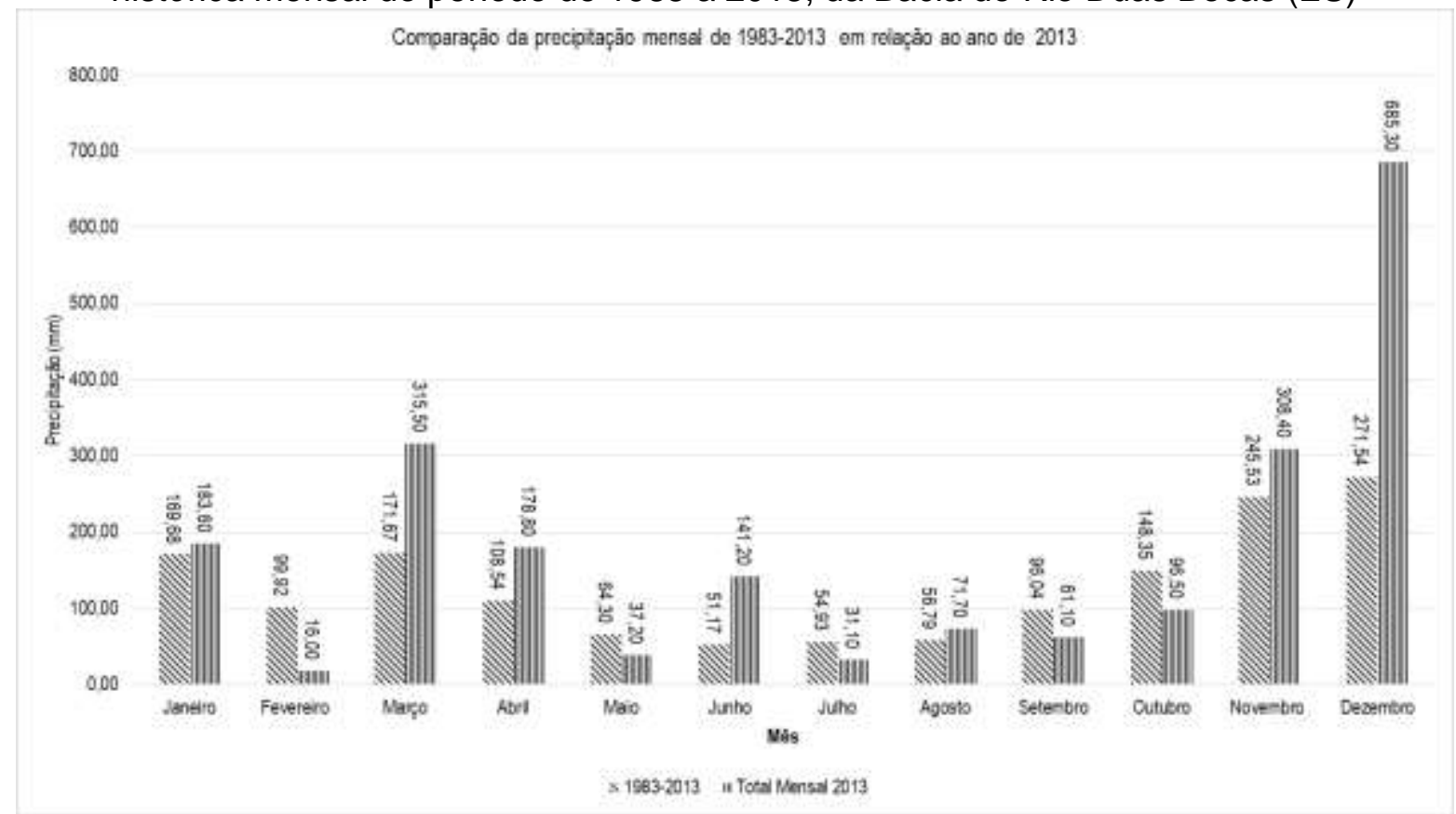

Fonte: Agência Nacional de Águas (2015) e Instituto Capixaba de Pesquisa e Extensão Rural (2015).

O desvio positivo de precipitação acumulada verificado para o mês dezembro de 2013 está, segundo o Instituto Capixaba de Pesquisa, Assistência Técnica e Extensão Rural (INCAPER), diretamente associado ao canal de umidade promovido pela atuação da Zona de Convergência do Atlântico Sul (ZCAS), que manteve o tempo encoberto e chuvoso em grande parte do Espírito Santo no referido mês (Figura 6). Souza et al. (2014) verificou, também, durante o mês de dezembro de 2013 que a ZCAS atuou em todo o Espírito Santo, sendo responsável, em geral, por $90 \%$ de toda a precipitação mensal desse estado. Ainda segundo esse autor, para a capital Vitória a ZCAS promoveu o aumento em $300 \%$ da precipitação pluvial acumulada do mês de dezembro. 
Figura 4 - Mapa de Distribuição espacial da chuva na BHRDB, da série histórica de 19832013

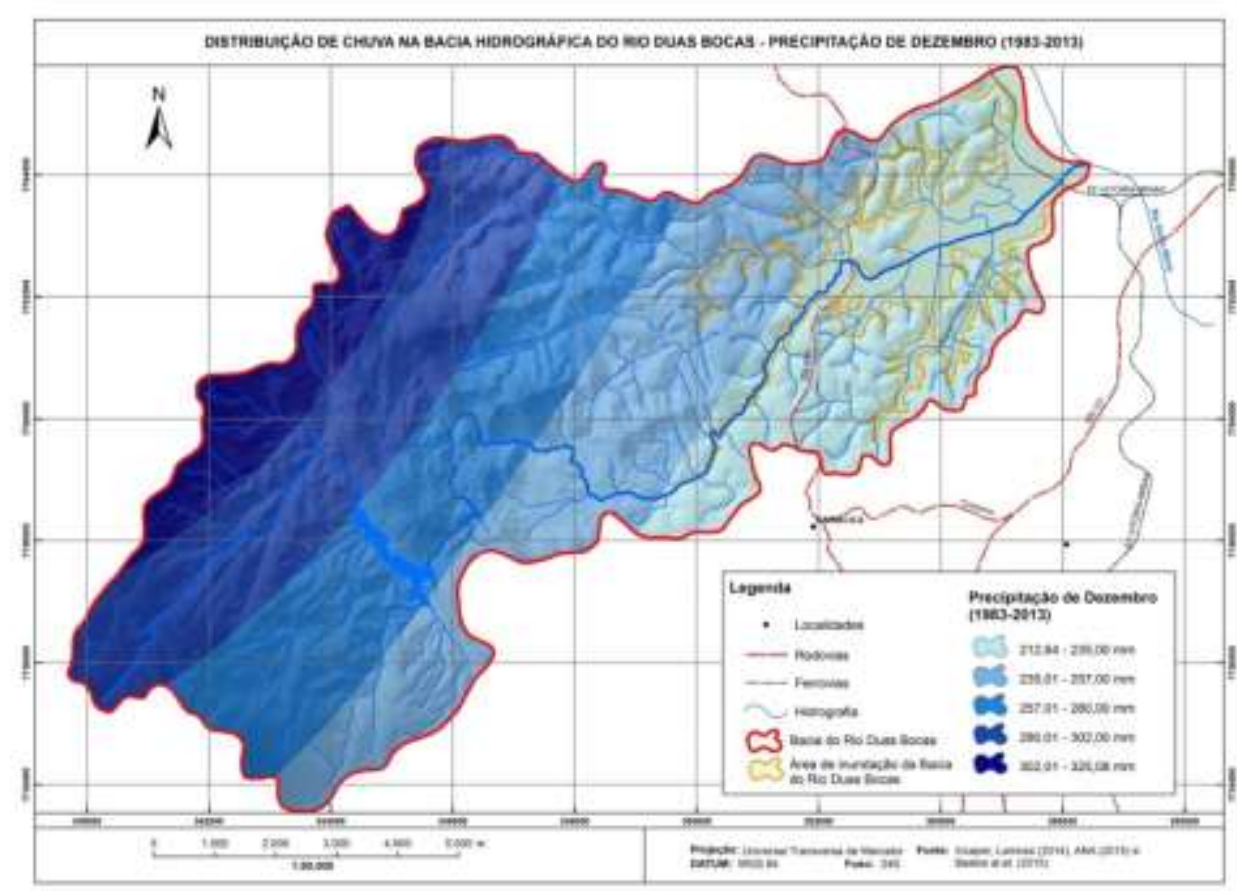

Fonte: Agência Nacional de Águas (2015) e Bastos et al. (2015).

Figura 5 - Mapa de Distribuição espacial da chuva na BHRDB, do mês de dezembro de 2013

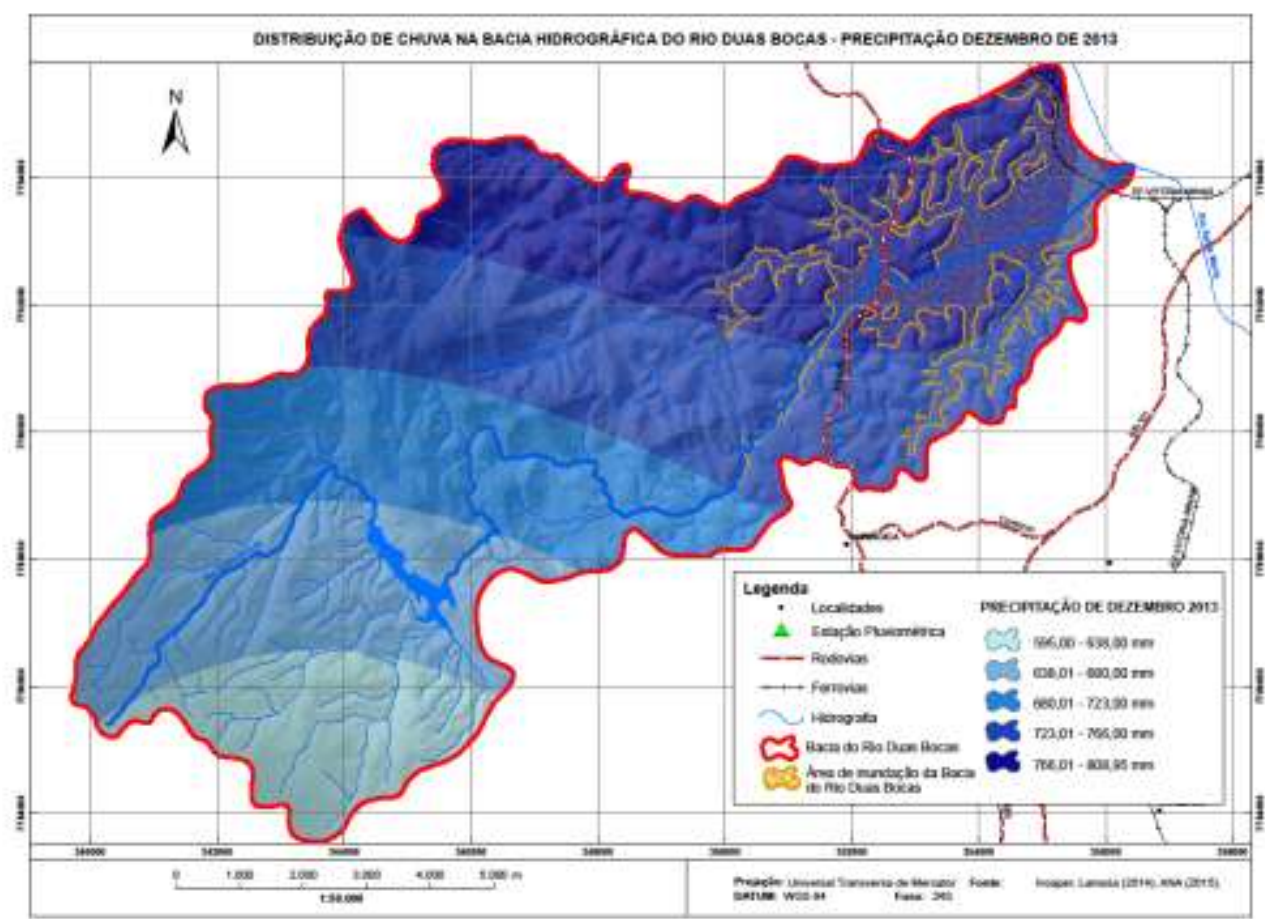

Fonte: Agência Nacional de Águas (2015) e Bastos et al. (2015).

Corroborando o observado nesse trabalho, Silva (2013) e Marchioro, Silva e Correa (2016) salientam que a Zona de Convergência do Atlântico Sul é a principal responsável 
pelo aumento do total acumulado de chuva na região metropolitana de Vitória. A relação entre a ZCAS e o aumento no volume acumulado de precipitação também foi verificada em trabalhos para o sudeste brasileiro desenvolvidos por Sant'Anna Neto (2005), Santos e Fialho (2016), Dutra et al. (2018) e Lima e Cupolillo (2018).

Figura 6 - Imagem de satélite infravermelho exemplificando a atuação da ZCAS em dezembro de 2013 na bacia hidrográfica do rio Duas Bocas na Região Metropolitana de Vitória (ES)

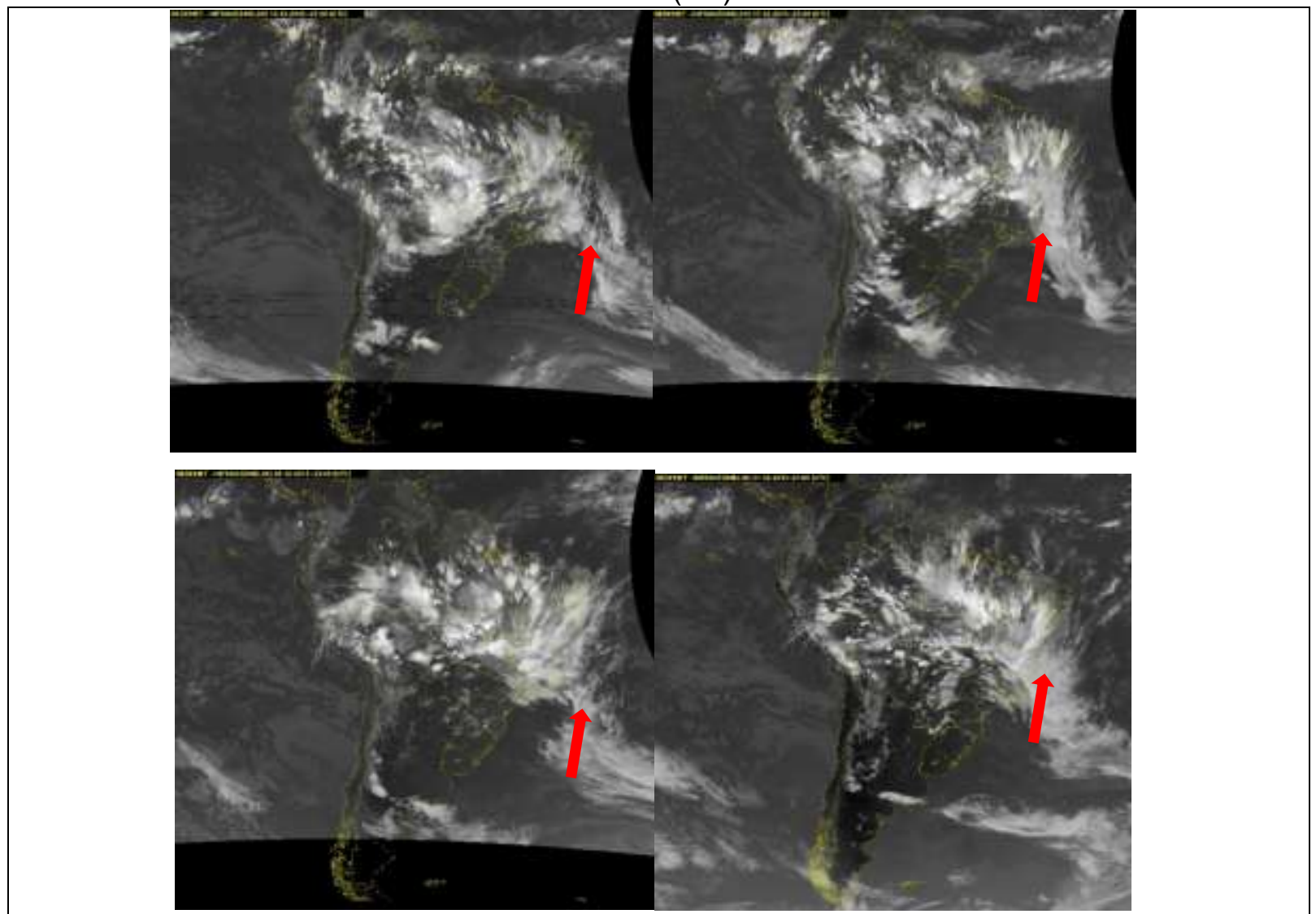

Fonte: Instituto de Pesquisa Espacial (2020).

Inter-relação entre o efeito de barramento promovido pelo rio Santa Maria da Vitória, com a inundação da bacia hidrográfica do rio Duas Bocas

A fim de verificar o efeito de remanso promovido pelo rio Santa Maria da Vitória sobre o seu tributário, o rio Duas Bocas, são apresentados os seus dados fluviométricos (vazão) ao longo do período de inundação de dezembro de 2013 e da série fluviométrica de 1950 a 2013.

Na Figura 7 é possível verificar que as maiores vazões médias anuais do rio Santa Maria da Vitória ocorreram nos anos de 1960, com 33,98m³/seg, em 1979, com $30,34 \mathrm{~m}^{3} / \mathrm{seg}$, e em 2013 , com $32,94 \mathrm{~m}^{3} / \mathrm{seg}$, sendo esta última a segunda maior vazão da série histórica. 
Figura 7 - Vazão anual média do rio Santa Maria da Vitória, entre 1950 e 2014 Ritmo anual médio de vazão do rio Santa Maria da Vitória entre 1950 e 2014.

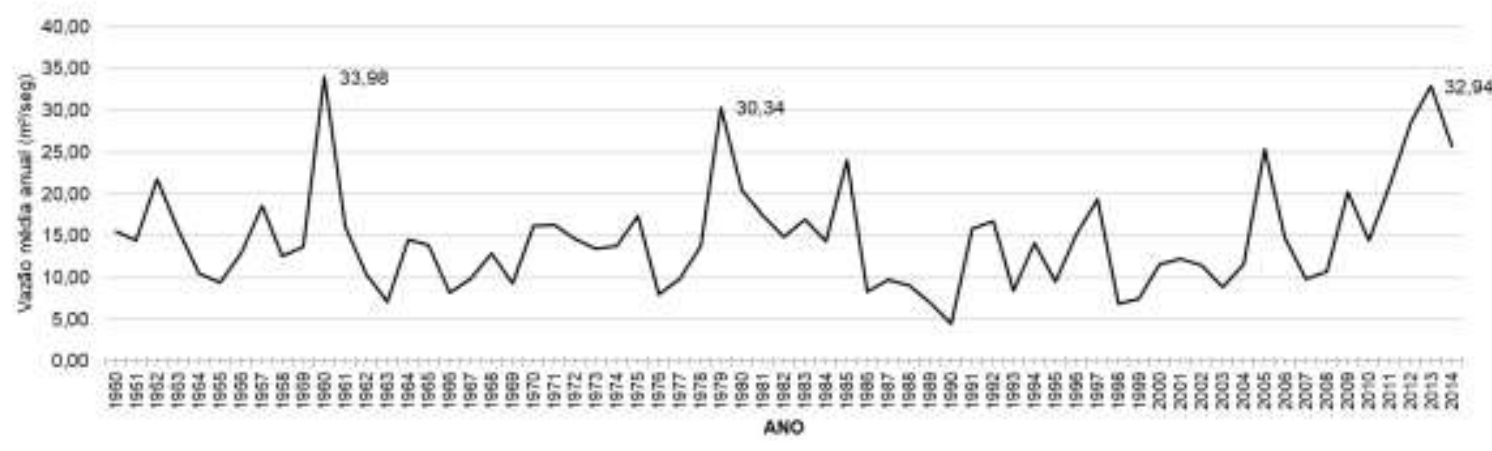

Fonte: Agência Nacional de Águas (2015).

Os dados de vazões máximas, médias e mínimas mensais de 2013 e 2014 do rio Santa Maria da Vitória são apresentados na Figura 8. Verifica-se que os picos de vazões nas categorias máximas e médias concentram-se nos meses de novembro e dezembro de 2013. Tal período é coincidente com o regime de precipitação pluvial da normal climatológica e, especificamente para o ano de 2013, ocorre um aumento substancial da vazão fluvial em função do desvio positivo da precipitação pluvial promovido pela atuação da ZCAS (Figura 6).

Figura 8 - Vazões máximas e mínimas, média mensal do rio Santa Maria da Vitória entre 2013 e 2014

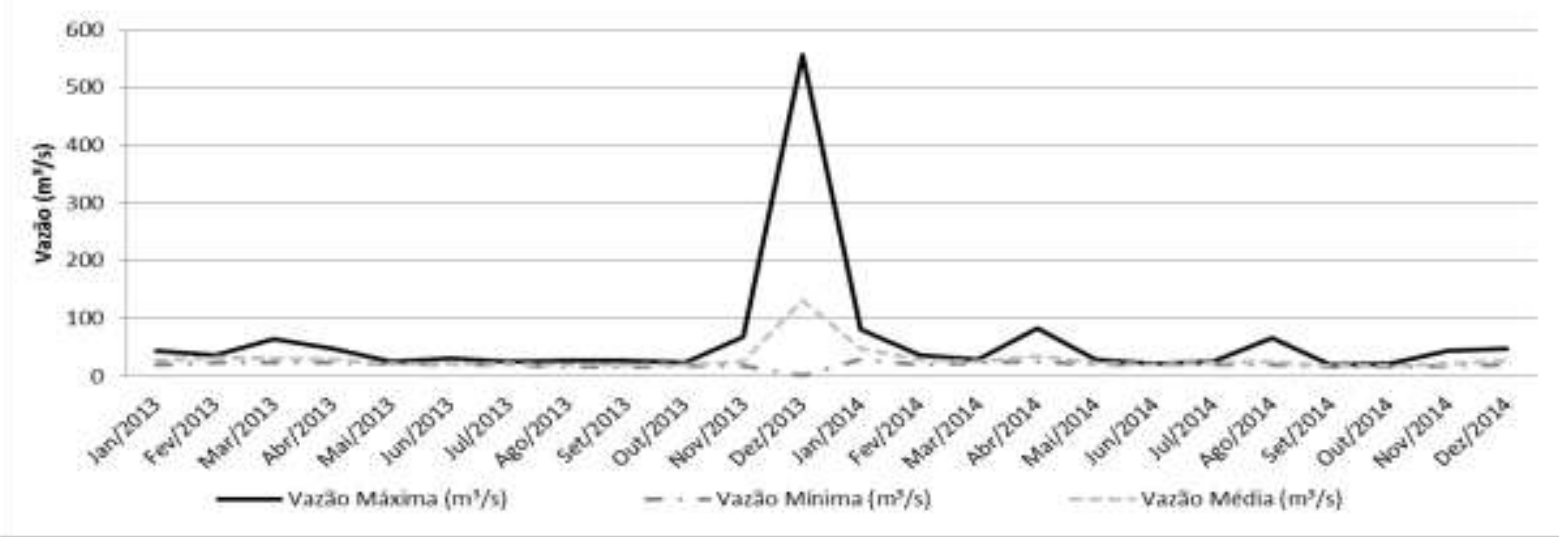

Fonte: Agência Nacional de Águas (2015).

As maiores cotas média mensais para período de 1970-2013 do rio Santa Maria da Vitória ocorreram nos meses de dezembro e janeiro, respectivamente com 158,14 centímetros e 160,41 centímetros. Quando se compara a cota mensal média como a 
encontrada no ano de dezembro de 2013, observa-se que em dezembro de 2013 a cota foi 389 centímetros, ou seja, o dobro da média histórica (Figura 9). Analisando apenas o período do efeito da ZCAS, verificaram-se valores médios de 492,94 centímetros, sendo que no dia 21 de dezembro de 2013 a cota atingiu o valor de 1.100 centímetros, reflexo do acumulado ao longo do período analisado.

Figura 9 - Cotas (centímetros) do rio Santa Maria da Vitória no Município de Santa Leopoldina (ES)

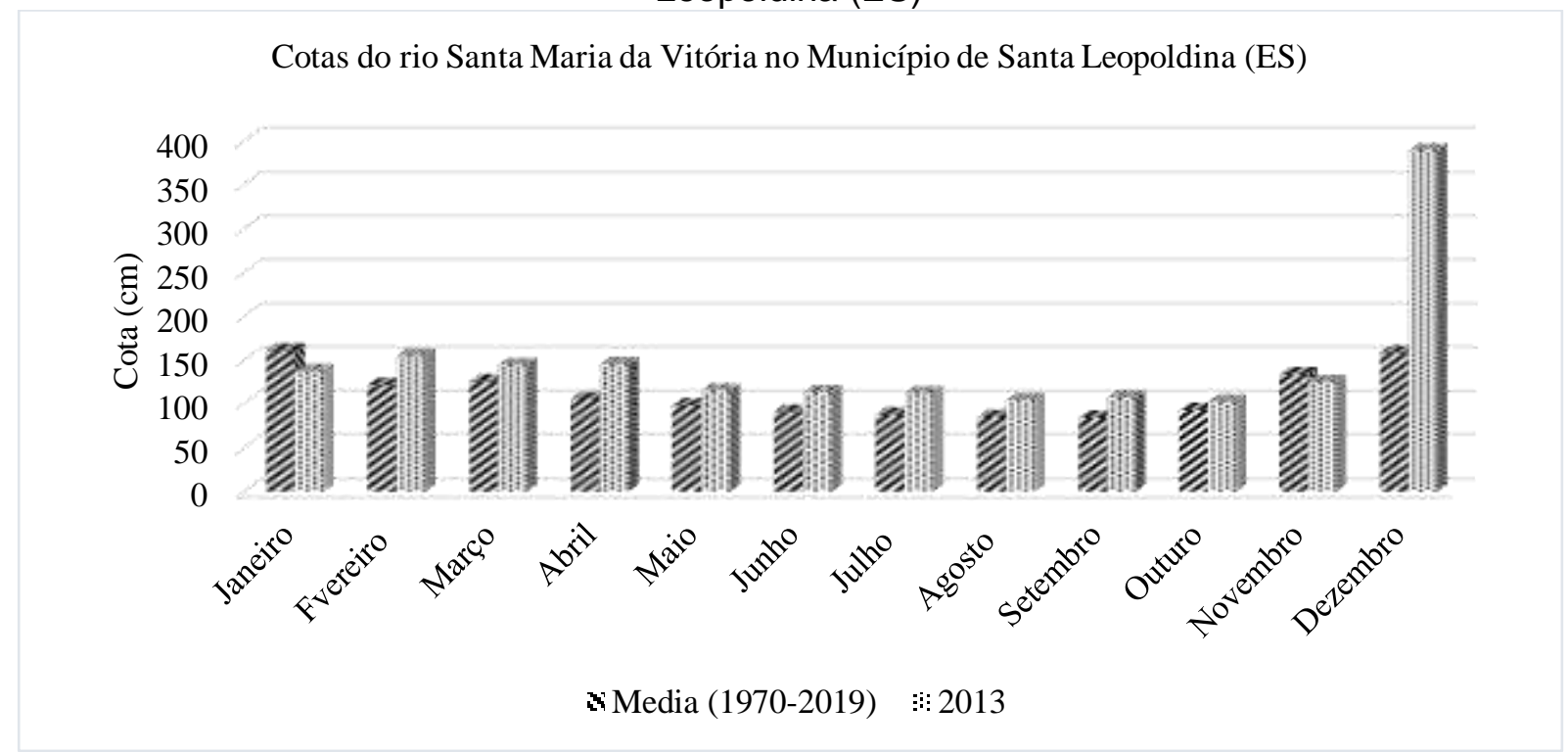

Fonte: Agência Nacional de Águas (2015).

Tal relação verificada neste trabalho entre ZCAS e vazão também foi identificada por Deina e Coelho (2015) para o rio Jucu na Região Metropolitana de Vitória, onde constataram que as maiores vazões e inundações estiveram associados a ZCAS. Reboita et al. (2017) relatam que os episódios de inundação e alagamento ocorridos na cidade de Itajubá, em janeiro de 1991 e 2000, estiveram também associados à atuação da Zona de Convergência do Atlântico Sul.

O valor do coeficiente de Pearson obtido entre os dados da série histórica de Vazão Média Anual e Precipitação anual do Rio Santa Maria da Vitória indicam uma correlação satisfatória positiva entre as variáveis, com índice de 0,6783 , ou seja, o aumento na precipitação representa aumento da vazão e, consequentemente, do nível do rio.

A partir do teste de Pearson, pode-se inferir que há relação direta entre as variáveis de vazão e precipitação acumulada anual. A relação entre a precipitação e a vazão do rio Santa Maria reforça que a elevada precipitação na bacia do rio Santa Maria da Vitória contribuiu para a elevação da sua cota e vazão e, por consequência, o rio Duas Bocas, contribuinte do rio Santa Maria da Vitória, apresentou limitação quanto ao seu desague, sendo que sua vazão sofreu barramento, contribuindo para a criação de uma zona de remanso, 
promovendo a inundação na BHRDB próximo à confluência, que repercutiram a montante do exutório.

O efeito remanso, verificado nesse trabalho, é apresentado por Christofoletti (1981), destacando que esse é um dos fatores que contribuem para a inundação fluvial em subbacias, que possuem seu deságue alterado pelo rio principal, fazendo-se necessário analisar esse efeito sobre as análises de inundação fluvial, pois é um fator relevante dentro do contexto geoambiental.

\section{O mapeamento da inundação na bacia hidrográfica do rio Duas Bocas}

Como pode ser visto na Figura 10, a BHRDB apresentou inundação no mês de dezembro de 2013, com maior ênfase para a porção inferior, ou seja, no baixo curso, onde predominam as maiores planícies de inundação e a desembocadura de contato com a Bacia do rio Santa Maria da Vitória, da qual a BHRDB é sub-bacia.

Figura 10 - Mapa da área inundada na bacia hidrográfica do rio Duas Bocas (ES)

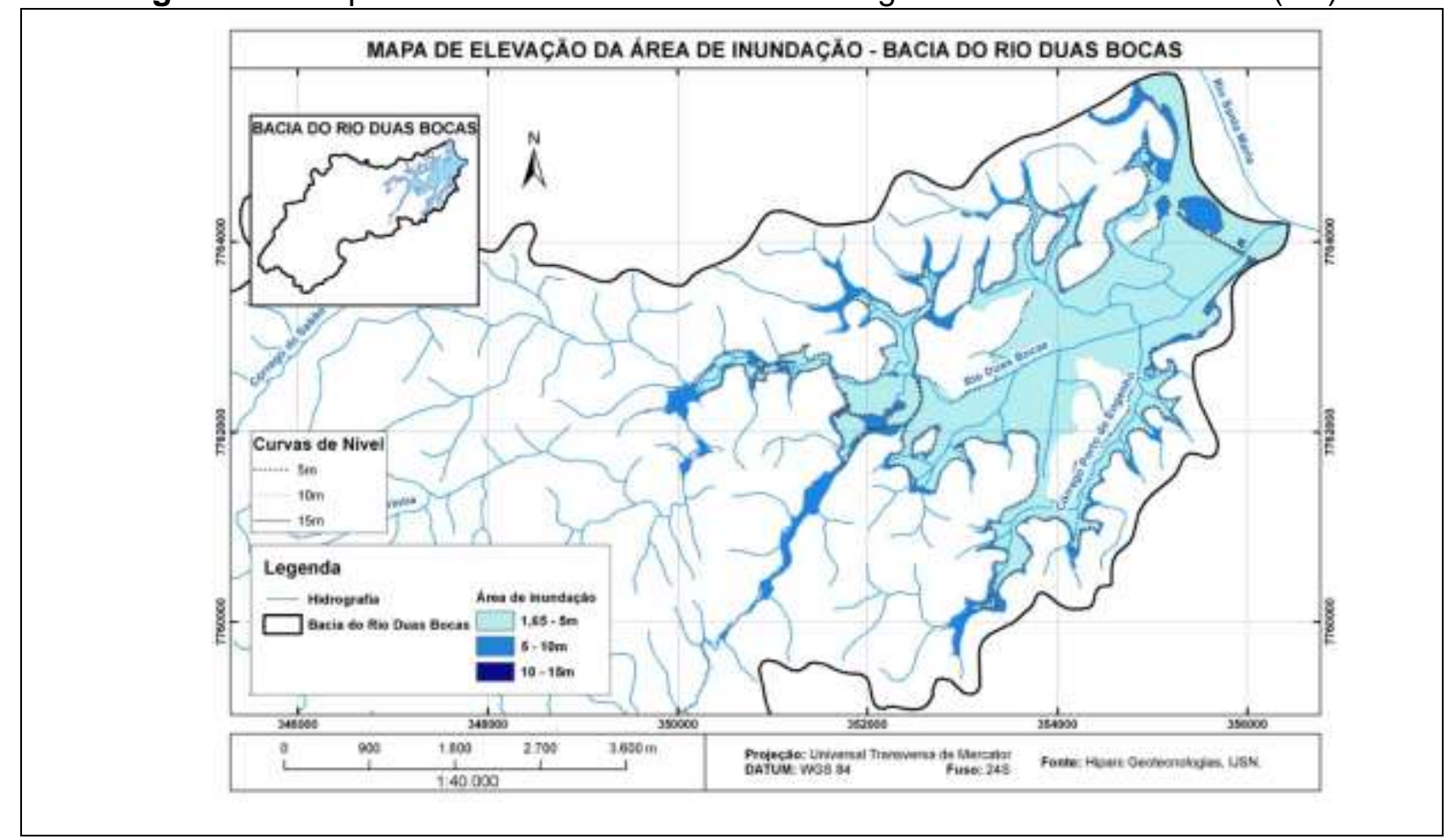

Fonte: os próprios autores (2015).

A área total inundada da bacia hidrográfica do rio Duas Bocas foi de 8,95 quilômetros quadrados, equivalendo a 9,69\% de área da bacia. As cotas altimétricas atingidas pela inundação na bacia variaram entre 1,65 e 15 metros, com altura da lâmina da água na porção inferior ou próximo ao exutório, entre as cotas de 1,65-10 metros de até 1,5 metros, e em cotas de entre 10 e 15 metros, próximo de 1 metro de altura (Figuras 10 e 11). As 
cotas entre 1,65 e 5 metros abrangeram $74,84 \%$ de área inundada, enquanto as cotas entre 5 e 10 metros abrangeram 24,12\% da área, que em conjunto totalizaram 98,96\% da área inundada. O restante das áreas inundadas ocorreu entre as cotas altimétricas de 10-15 metros, abrangendo apenas $1,04 \%$ da área inundada, que é de difícil visualização no mapa.

Figura 11 - Planície de inundação na transição do terço inferior ao médio da bacia do rio Duas Bocas (ES)

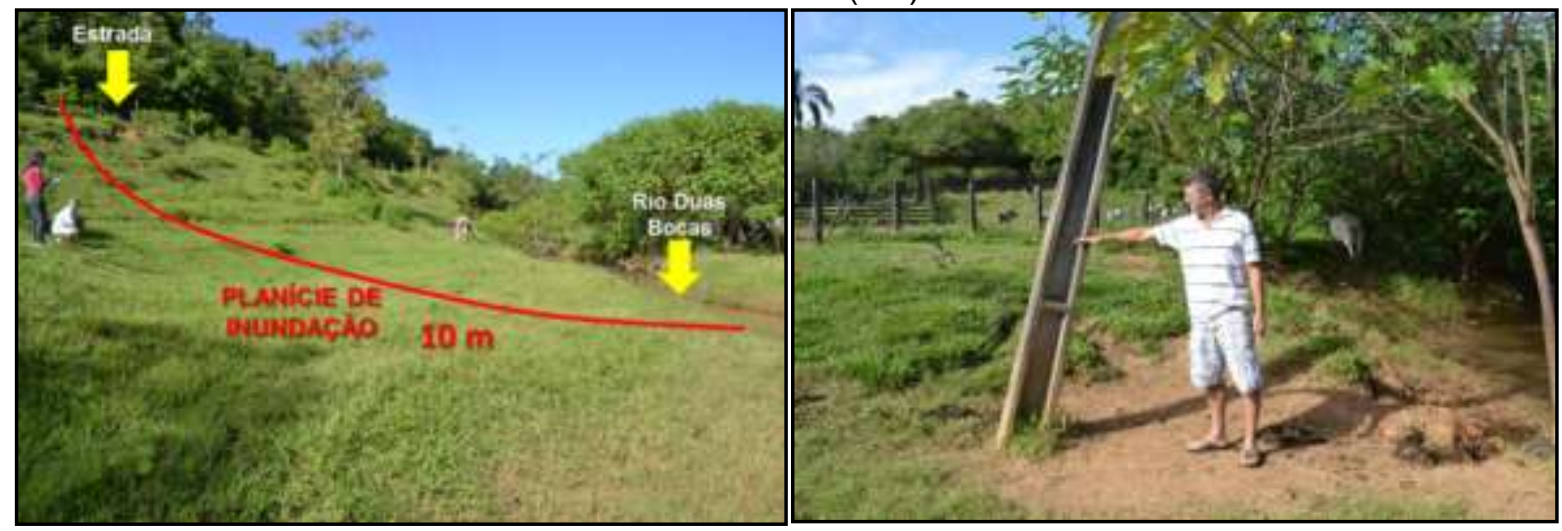

Fonte: os próprios autores (2015).

A inundação ocorrida na cota de até 16 metros evidencia o longo alcance que teve na BHRDB, uma vez que nestas cotas as planícies de inundações são estreitas, quase sempre utilizadas para fins agrícolas e edificações para residências. A maior ocorrência de inundação no terço inferior da BHRDB foi em cota inferior a 10 metros, consequência da convergência de águas de escoamento superficial e subsuperficial, que drenam para a porção mais baixa da bacia.

Outro aspecto que contribuiu para a inundação foram os maiores totais pluviométricos na porção média a inferior da BHRDB, promovidos pela Zona de Convergência do Atlântico Sul (Figuras 2 e 6). Também, o efeito de barramento (obstáculo de deságue) promovido pelo fluxo de água do rio Santa Maria da Vitória (canal principal) em relação ao rio Duas Bocas (canal tributário) teve influência sobre a inundação da planície.

Em relação ao uso e a cobertura da terra das áreas inundadas, é possível verificar na Tabela 1 e na Figura 12 que predominou a área de Pastagem, com 64,82\%, seguida por Brejo (22,61\%), Matas Naturais (6,60\%) e Cultivo Agrícola - Outros cultivos Agrícolas Anuais mostraram 3,52\%. Nota-se que as características encontradas de uso e cobertura da terra são representativas de áreas rurais da BHRDB.

As áreas da planície de inundação da BHRDB destinadas à agricultura são diversificadas quanto ao tipo de cultivo, mas no caso dos cultivos anuais ocorre em $3,52 \%$. A presença de edificações para residências $(1,35 \%)$ se concentra no terço médio e superior da BHRDB e, de acordo com Santos e Marchioro (2018, 2020), estão em expansão nos limites da bacia sem levar em consideração o estabelecido pelo atual 
Código Florestal Brasileiro, corroborando para futuras inundações, uma vez que alteram as relações hidrológicas na bacia.

Tabela 1 - Uso e ocupação da terra da área de inundação da bacia do rio Duas Bocas (ES)

\begin{tabular}{l|c|r}
\hline Classes & Área $\left.\mathbf{( k m}^{\mathbf{2}}\right)$ & Percentual (\%) \\
\hline Pastagem & 5,80 & 64,82 \\
\hline Brejo & 2,02 & 22,61 \\
\hline Mata Nativa & 0,59 & 6,60 \\
\hline Outros cultivos Anuais & 0,31 & 3,52 \\
\hline Edificação & 0,12 & 1,35 \\
\hline Macega & 0,05 & 0,56 \\
\hline Cultivo agrícola - Côco Bahia & 0,02 & 0,23 \\
\hline Cultivo Agrícola - Café & 0,01 & 0,16 \\
\hline Solo exposto & 0,01 & 0,11 \\
\hline Massa de água & 0,00 & 0,05 \\
\hline Total & 8,95 & 100,00 \\
\hline
\end{tabular}

Fonte: os próprios autores (2015).

Figura 12 - Uso e cobertura da terra na área de inundação da bacia hidrográfica do rio Duas Bocas (ES)

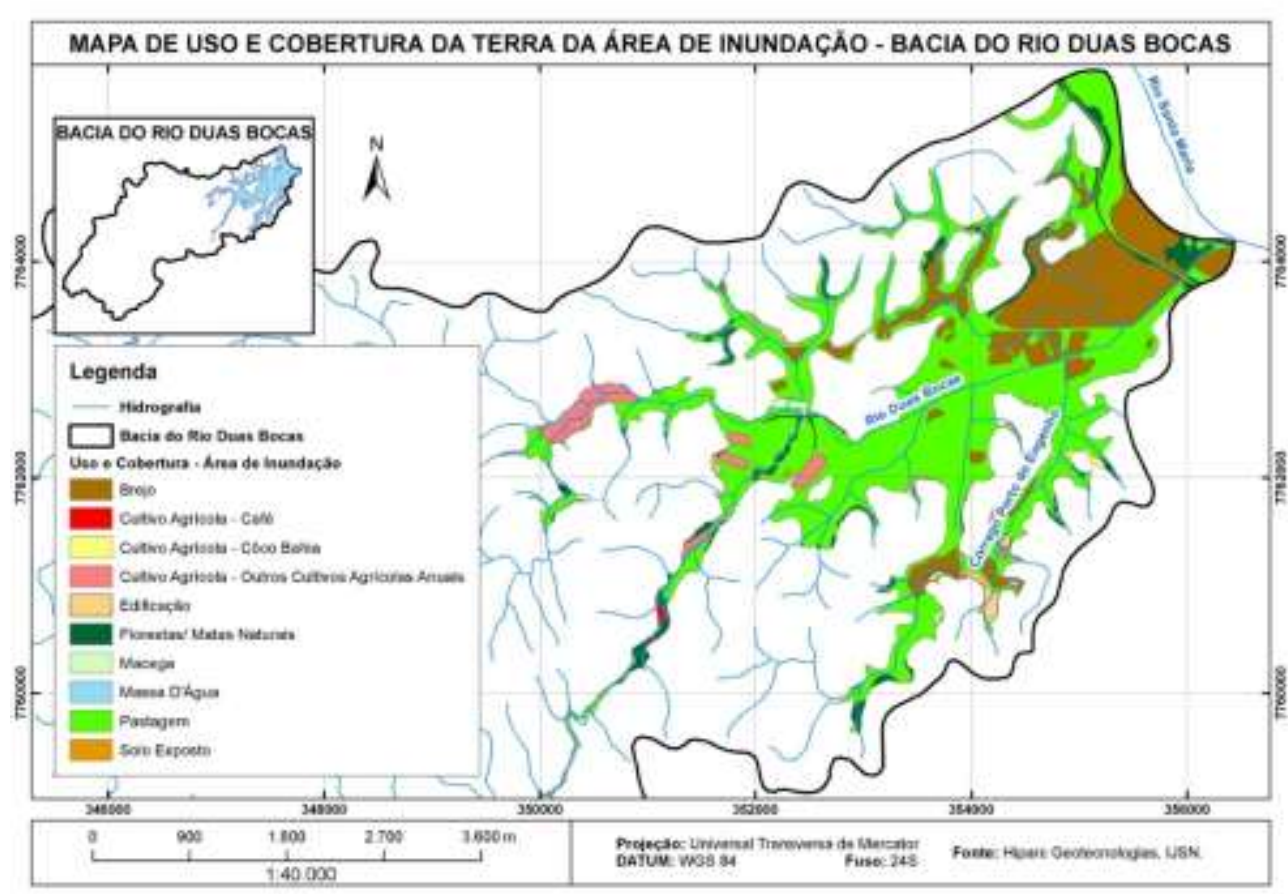

Fonte: os próprios autores (2020).

As classes pastagens e cultivos anuais são elementos que contribuem para o processo de inundação na $B H R D B$, uma vez que são realizadas sem práticas de manejo e conservação do solo adequada, dificultando o processo de infiltração e contribuindo para o escoamento superficial. Nesse sentido, Santos e Marchioro (2018) salientam, também, 
que as áreas com maior produção de sedimentos por escoamento superficial estão associadas às áreas de pastagens e cultivos agrícolas anuais na BHRDB. Costa (2001) também encontrou relação semelhante entre o aumento da inundação e as alterações no uso e cobertura da terra para o Rio de Janeiro, ao afirmar que estão influenciando os processos de infiltração pelo aumento da impermeabilização e escoamento superficial.

Por sua vez, Damasco, Furtado e Bento-Gonçalves (2014), na bacia rural do rio Luís Alves, verificaram por meio de mapeamento que as alterações antrópicas (principalmente associadas aos cultivos cana-de-açúcar, palmeiras e arroz que se encontram prioritariamente na planície) sobre o uso e a cobertura da terra que associados as características morfométricas da bacia contribuíram para a inundação para cotas de até 7 metros, sendo mais recorrentes aquelas cotas de até 2 metros.

\section{CONCLUSÕES}

As áreas inundadas no evento extremo de dezembro de 2013 estiveram associadas à precipitação acima da média histórica da área da bacia hidrográfica do rio Duas Bocas, oriundas do efeito da Zona de Convergência do Atlântico Sul.

O aumento da vazão do rio Santa Maria da Vitória em dezembro de 2013 estabeleceu uma zona de barramento e de remanso sobre a planície congruente do rio Duas Bocas, impedindo o deságue deste último rio, fato que colaborou para a intensificação e ampliação das áreas inundadas.

As áreas onde ocorreu maior inundação estão situadas entre as cotas de 1,65 e 10 metros, que totalizam $98,13 \%$, predominando uso e cobertura da terra para a pastagem e de brejos, com participação de áreas agrícolas, associadas principalmente ao cultivo de café, que ocorre em planícies estreitas entre as cotas de 30 a 60 metros de altitude. Também é relevante destacar a pequena influência das inundações sobre a classe edificações, uma vez que a BHRDB é predominante rural.

O processo de inundação apresentou variações associados ao ritmo de precipitação, exigindo por parte de gestores e planejadores de uso e cobertura da terra, medidas estruturais e não estruturais nas suas diferentes esferas que devem garantir a proteção para diferentes finalidades socioambientais.

\section{REFERÊNCIAS}

AGÊNCIA NACIONAL DE ÁGUAS (Brasil). Hidroweb. Brasília, DF: ANA, 2015. Disponível em: http://www.snirh.gov.br/hidroweb/serieshistoricas. Acesso em: 25 maio 2015. 
ALCRUDO, Francisco. A State-of-the-art review on mathematical modelling of flood propagation. 2016. Disponível em: http://www.impact-project.net/cd/papers/print/008_pr_0205-16_IMPACT_Alcrudo.pdf. Acesso em: 25 jan. 2020.

AMORIM, Leonardo Nunes. O efeito da escala na análise geomorfológica da sub-bacia hidrográfica do rio Duas Bocas, tributário da bacia hidrográfica do rio Santa Maria da Vitória - ES. 2014. Trabalho de Conclusão de Curso (Graduação em Geografia) Universidade Federal do Espírito Santo, Vitória, ES, 2014.

ARDUINO, Gabriel; REGGIANI, Paolo; TODINI, Ezio. Recent advances in flood forecasting and flood risk assessment. Hydrology and Earth System Sciences Discussions, Milão, v. 9, n. 4, p. 280-284, 2005. Disponível em: https://hal.archives-ouvertes.fr/hal00304828/document. Acesso em: 26 maio 2015.

BASTOS, Ketlen Victor; LOPEZ, Juan Felipe Barrios; GONÇALVES, Alexandre Ortega; MARCHIORO, Eberval. Ritmo pluviométrico da bacia do rio Duas Bocas (ES). In: SIMPÓSIO INTERNACIONAL DE ÁGUAS, SOLOS E GEOTECNOLOGIAS, 2015, Uberaba. Anais [...]. Uberaba: Compact Disc Read-only Memory, 2015. p. 1-10.

BRUNNER, Gary W. HEC-RES river analysis system: user's manual version 5.0.us army corps of engineers. Davis: Hydrologic Engineering Center (HEC), 2016.

CAJAZEIRO, Joana Maria Drumond. Análise da susceptibilidade à formação de inundações nas bacias e áreas de contribuição do ribeirão Arrudas e córrego da Onça em termos de índices morfométricos e impermeabilização. 2012. Dissertação (Mestrado em Geografia) - Universidade Federal de Minas Gerais, Belo Horizonte, 2012.

CENTRO DE ESTUDOS E PESQUISAS DE DESASTRES NATURAIS - CEPEDES. Atlas brasileiro de desastres naturais 1991 a 2012. Florianópolis: CEPED/UFSC, 2013.

CHRISTOFOLETTI, Antônio. Geomorfologia fluvial. São Paulo: Blucher: Fundação de Amparo à Pesquisa do Estado de São Paulo, 1981.

COSTA, Helder. Enchentes no estado do Rio de Janeiro: uma abordagem geral. Rio de Janeiro: SEMADS, 2001.

CUPERTINO, Wallace; SANTOS, James Rafael Ulisses; MARCHIORO, Eberval. Análise da distribuição granulométrica do reservatório da reserva biológica de Duas Bocas - Cariacica (ES). In: CONGRESSO INTERNACIONAL DE HIDROSSEDIMENTOLOGIA, 1., 2015, Porto Alegre, Rs. Anais [...]. Porto Alegre, RS: UFRGS, 2015. p. 56 - 60.

DAMASCO, Fernando Souza; FURTADO, Thales Vargas; BENTO-GONÇALVES, Antônio José. Risco de inundação em áreas rurais: bacia do rio Luís Alves (SC). Geografia Ensino \& Pesquisa, Santa Maria, v. 18, n. 1, p. 99-117, jan./abr. 2014. Disponível em: https://periodicos.ufsm.br/geografia/article/view/8902/0. Acesso em: 26 maio 2015.

DEINA, Miquelina Aparecida; COELHO, André Luiz Nascentes. A Influência da Zona Convergência do Atlântico Sul (ZCAS) nos Eventos de Inundação no Baixo Jucu em Vila Velha (ES). Geografia, Londrina, v. 24, n. 2, p. 5-23, jul./dez. 2015. Disponível em: http://www.uel.br/revistas/uel/index.php/geografia/article/view/19125. Acesso em: 25 set. 2015.

DUTRA, Flávia Regina Lacerda Suassuna; QUADRO, Mário Francisco Leal; MÜLLER, Gabriela Viviana; VALADÃO, Roberto Célio. Associações entre a Zona de Convergência do Atlântico Sul e o El Niño e sua influência sobre a distribuição espaço-temporal da Leptospirose em Minas Gerais. Hygeia, Uberlândia, v. 14, n. 27, p.1-13, 2018.

EMBRAPA - Empresa Brasileira de Pesquisa Agropecuária. Sistema brasileiro de classificação de solos. Rio de Janeiro, RJ: Centro Nacional de Pesquisa de Solos, 2013.

ENVIRONMENTAL SYSTEMS RESEARCH INSTITUTE - ESRI. User manual: help online. Version 10.1. 2012. 
GOUDIE, Andrew. Encyclopedia of geomorphology. London: Taylor \& Francis Group, 2004.

HORA, Silmara Borges; GOMES, Ronaldo Lima. Mapeamento e avaliação do risco a inundação do rio Cachoeira em trecho da área urbana do município de Itabuna/BA. Revista Sociedade \& Natureza, Uberlândia, v. 21, n. 2, p. 57-75, 2009. Disponível em: http://www.seer.ufu.br/index.php/sociedadenatureza/article/view/9583. Acesso em: 2 jul. 2018.

INSTITUTO CAPIXABA DE PESQUISA, ASSISTÊNCIA TÉCNICA E EXTENSÃO RURAL INCAPER. Coordenação de meteorologia. Disponível em: https://meteorologia.incaper.es.gov.br/estacoes-do-ano. Acesso em: 28 jun. 2015.

INSTITUTO DE PESQUISA ESPACIAL - INPE. Coordenação geral de observação da Terra. 2020. Disponível em: http://www.dgi.inpe.br/. Acesso em: 23 maio 2020.

INSTITUTO JONES SANTOS NEVES - IJSN. Mapeamento geomorfológico do Estado do Espírito Santo. Vitória, ES: IJSN, 2012. (Nota técnica, 28).

LIMA, Jean Monteiro; CUPOLILLO, Fulvio. Análise espaço-temporal das chuvas persistentes na região do Parque Estadual do Rio Doce-Per, sob a influência das Zcas e Zcou (out/2015 a dez/2016). Revista Brasileira de Climatologia, Curitiba, ano 14, p. 25-47, 2018.

Disponível em: https://revistas.ufpr.br/revistaabclima/article/view/59298. Acesso em: 23 jun. 2019.

LOPEZ, Juan Felipe Barrios; MARCHIORO, Eberval. Interceptação de águas pluviais na reserva biológica de Duas Bocas. Beau Bassin: Novas Edições Acadêmicas, 2018.

MAGALHÃES, Ivo Lopes; THIAGO, Carlos Roberto; AGRIZZI, Daniela Vantill; SANTOS, Alexandre Rosa. Uso de geotecnologias para mapeamento de áreas de risco de inundação em Guaçuí, ES: uma análise comparativa entre dois métodos. Cadernos de Geociências, Salvador, v. 8, n. 2, p. 63-70, 2011. Disponível em:

https://portalseer.ufba.br/index.php/cadgeoc/article/view/5288. Acesso em: 5 maio 2020.

MARCHIORO, Eberval et al. Hidrossedimentologia de uma bacia hidrográfica na região serrana do Espírito Santo (Brasil). In: CONGRESSO INTERNACIONAL DE

HIDROSSEDIMENTOLOGIA, 2., 2017, Foz do Iguaçu, PR. Anais [...]. Rio de Janeiro:

Compact Disc Read-only Memory, 2017. p 1 - 7.

MARCHIORO, Eberval. A incidência de frentes frias no município de Vitória (ES). Acta Geográfica, Boa Vista, p. 29-60, 2012. Disponível em:

https://pdfs.semanticscholar.org/4c36/fa5129716d85a5115e87139363f14f6a2319.pdf. Acesso em: 17 out. 2015.

MARCHIORO, Eberval; BARROSO, Gilberto Fonseca. Avaliação de sólidos transportados, parâmetros da morfometria e solos de seções fluviais do córrego Naiá-assú (Reserva Biológica de Duas Bocas/ES. Caderno de Pesquisa, Vitória, ES, v. 1, n. 1, p. 185-195, 1996.

MARCHIORO, Eberval; SILVA, Graziani Mondoni; CORREA, Wesley Souza Campos. A Zona de Convergência do Atlântico Sul e a precipitação pluvial do Município de Vila Velha (ES): Repercussões sobre as inundações. Revista do Departamento de Geografia, São Paulo, SP, v. 31, p. 101-117, 2016. Disponível em:

http://www.revistas.usp.br/rdg/article/view/108447. Acesso em: 3 dez. 2015.

PENDER, G. Briefing: introducing the flood risk management research consortium.

Proceedings of the Institution of Civil Engineers - Water Management, London, v. 159, n. 1, p. 3-8, 2006. Disponível em:

http://citeseerx.ist.psu.edu/viewdoc/download?doi=10.1.1.615.5686\&rep=rep1\&type=pdf. Acesso em: 1 jun. 2020. 
PERRONE, Adriano. Estudos preliminares sobre a carga de sólidos transportados, parâmetros morfométricos e pluviométricos da bacia do córrego Pau Amarelo Reserva Biológica de Duas Bocas - ES. 1995. Trabalho de Conclusão de Curso (Graduação em Geografia) - Universidade Federal do Espírito Santo, Vitória, 1995.

PÔSSA, Evelyn Márcia; VENTORINI, Silvia Elena. Expansão urbana para áreas de risco de inundação e de movimento de massa: o estudo no município de São João Del-Rei - MG. Caderno Prudentino de Geografia, Presidente Prudente, v. 2, n. 36, p. 49-67, 2014. Disponível em: https://revista.fct.unesp.br/index.php/cpg/article/view/2619. Acesso em: 5 abr. 2020.

PRAKASH, Mahesh; ROTHAUGE, Kai; CLEARY, Paul W.; Modelling the impact of dam failure scenarios on flood inundation using SPH. Applied Mathematical Modelling, New York, v. 38, n. 23, p. 5515-5534, 2014. Disponível em:

https://www.sciencedirect.com/science/article/pii/S0307904X14001140. Acesso em: 4 dez. 2015.

QUEIROGA, Gláucia Nascimento; SOARES, Antônio Carlos Pedrosa; RONCATO JÚNIOR, Jorge Geraldo; DIAS, Paulo Henrique Amorim; GUIMARÃES, Henrique Alvim; COUTINHO, Mariana Oliveira Gondin; FREITAS, Natália Cota; GRADIM, Camila Tavares; BRAGA, Flávia Cristina Silveira; NOVO, Tiago Amâncio. Geologia e recursos minerais da folha Nova Venécia SE.24-Y-B-IV, estado do Espírito Santo, 153 escala 1:100.000. Belo Horizonte: CPRM, 2012.

REBOITA, Michelle Simões; MARIETTO, Diogo Malagutti Gonçalves; SOUZA, Amanda; BARBOSA, Mariana. Caracterização atmosférica quando da ocorrência de eventos extremos de chuva na região Sul de Minas Gerais. Revista Brasileira de Climatologia, Curitiba, v. 21, p. 20-37, jul. /dez. 2017. Disponível em:

https://revistas.ufpr.br/revistaabclima/article/view/47577. Acesso em: 4 abr. 2020.

SANT'ANNA NETO, João Lima. Decálogo de climatologia brasileira. Revista Brasileira de Climatologia, Curitiba, v. 1, n. 1, p. 1-18, 2005. Disponível em https://revistas.ufpr.br/revistaabclima/article/view/25232. Acesso em: 10 nov. 2016.

SANTOS, James Rafael Ulisses; MARCHIORO, Eberval. Análise empírica da fragilidade ambiental da bacia hidrográfica do Rio Duas Bocas, Espírito Santo, Brasil. Revista do Departamento de Geografia (USP), São Paulo, v. 39, p. 72-87, 2020. Disponível em: https://www.revistas.usp.br/rdg/article/view/160946. Acesso em: 13 jul. 2020.

SANTOS, James Rafael Ulisses; MARCHIORO, Eberval. Fragilidade emergente da bacia hidrográfica do rio Duas Bocas, Espírito Santo: uma análise integradora da paisagem. Revista Geografias (UFMG), Belo Horizonte, v. 26, n. 2, p. 8-30, 2018. Disponível em: https://periodicos.ufmg.br/index.php/geografias/article/view/19364. Acesso em: 15 fev. 2020.

SANTOS, Vitor Juste; FIALHO, Edson Soares. Zona de convergência do atlântico sul (Zcas) e impactos pluviais intensos: o caso da cidade de UBÁ/MG. Revista Brasileira de Climatologia, Curitiba, ano 12, v. 19, p. 218-238, jul./dez. 2016. Disponível em: https://revistas.ufpr.br/revistaabclima/article/view/35684. Acesso em: 18 set. 2019.

SCHUMANN, Guy; BATES, Paul D.; HORRITT, Matthew; MATGEN, Patrick. Progress in integration of remote sensing derived flood extent and stage data and hydraulic models.

Reviews of Geophysics, Washington, v. 47, n. 4, p. 2-20, 2009. Disponível em: https://www.researchgate.net/publication/228669784_Progress_in_integration_of_remote_se nsing-derived_flood_extent_and_stage_and_hydraulic_models. Acesso em: $2 \overline{5}$ jun. 2020.

SILVA, Graziani Mondoni. A zona de convergência do atlântico sul e a precipitação pluvial do município de Vila Velha (ES): repercussões sobre as inundações. 2013. Trabalho de Conclusão de Curso (Graduação em Geografia) - Universidade Federal do Espírito Santo, Vitória, 2013. 
SMITH, Laurence C. Satellite remote sensing of river inundation area, stage, and discharge: a review. Hydrological Processes, Chichester, v. 11, p. 1427-1439, 1997.

SOUZA, Lucio Silva; TAVARES, Armando de Sá; CUNHA, Anderson Eloi da Silva; CARVALHO, Marilen. ZCAS de dezembro de 2013 no Estado do Espírito Santo: atualizando a série histórica e previsão quantitativa das chuvas. In: CONGRESSO BRASILEIRO DE METEOROLOGIA, 18., 2014, Recife, PE. Anais [...]. Recife: CBMET, 2014. p. 1.

STRAHLER, Arthur N. Quantitative analysis of wastershed Geomorphology. Transaction of American Geophysics Union, Washington, 38. p. 913-920, 1957. Disponível em: https://agupubs.onlinelibrary.wiley.com/doi/10.1029/TR038i006p00913. Acesso: 19 maio 2020.

TICEHURST, Catherine; DUTTA, Dushmanta; KARIM, Fazlul; PETHERAM, Cuan; GUERSCHMAN, Juan Pablo. Flood mapping at a daily scale using MODIS imagery in large floodplains and reduction of uncertainty with the aid of hydrodynamic modelling. Natural Hazards, Dordrecht, v. 78, n. 2, p. 803-820, 2015. Disponível em: https://link.springer.com/article/10.1007/s11069-015-1743-5. Acesso em: 7 jun. 2020.

TRIGG, Mark A.; MICHAELIDES, Katerina; NEAL, Jeffrey C.; BATES, Paul D. Surface water connectivity dynamics of large-scale extreme flood. Journal of Hydrology, Amsterdam, v. 505, p. 138-149, 2013. Disponível em: https://researchinformation.bris.ac.uk/en/publications/surface-water-connectivity-dynamics-of-a-large-scaleextreme-floo. Acesso em: 19 maio 2020.

TUCCI, Carlos Eduardo Morelli. Controle de enchentes. In: TUCCI, Carlos Eduardo Morelli; SILVEIRA, André Luiz Lopes. Hidrologia: ciência e aplicação. Porto Alegre: UFRGS/ ABRH, 2004. p. 622-658.

WANG, Shudong; BAIG, Muhammad Hasan Ali; ZHANG, Lifu; JIANG, Hailiang; JI, Yuhe; ZHAO, Hengqian; TIAN, Jingguo. A simple enhanced water index (EWI) for percent surface water estimation using landsat data. IEEE Journal of Selected Topics in Applied Earth Observations and Remote Sensing, Boston, v. 8, n. 1, p. 90-97, 2015. Disponível em: https://ieeexplore.ieee.org/document/7027774. Acesso em: 10 maio 2020.

WOLMAN, M. Gordon; LEOPOLD, Luna B. River flood plains: some observations on their formation. Geological Survey Professional, Washington, Paper 282-C, p. 87-107, 1957. Disponível em: https://pubs.usgs.gov/pp/0282c/report.pdf. Acesso em: 10 jul. 2017.

WOODHEAD, Simon; ASSELMAN, Nathalie; ZECH, Yves; SOARES-FRAZÂO, Sandra; BATES, Paul. Evaluation of inundation models. Report number T08-07-01. Delf: Delft Hydraulics, 2007.

Recebido: junho de 2020. Aceito: outubro de 2020. 